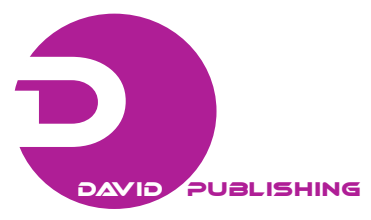

\title{
Limitations of Cost Estimation Using Building Information Modeling in Poland
}

\author{
Krzysztof Zima and Agnieszka Leśniak \\ Department of Building Technology and Organization, Faculty of Civil Engineering, Cracow University of Technology, Warszawska \\ 24 31-155, Poland
}

\begin{abstract}
BIM (building information modeling) is a technological innovation, not only during the design process, but also during the planning and preparation stages of a construction project, as it also supports making investment decisions. An innovation which is comparable, if only slightly less significant, was the transition from using 2D systems to the 3D structural model design. The article outlines the advantages of using BIM in the preparatory stages of a construction project. It also presents benefits which relate to the employment of the BIM system in cost estimation process. The article describes the Zuzia BIM system which uses the BIM model, as this system has just been created in Poland for the purpose of construction cost estimation. The preparation of the bill of quantities is automated in this system and this has been achieved on the basis of data directly obtained from virtual models of buildings, which were carried out thanks to the collaboration of various design sectors. The article authors, using their own experience, present difficulties which can be encountered by cost estimators in Poland when calculating the value of a building with the help of the BIM concept. The article shows the design errors that prevent or hinder takeoff automatic calculation based on BIM model. Design errors shown in the article are for example reinforcement bars have been defined by a designer as elements hollow in the middle or as one element for the whole building, one type of elements assigned as few different or incorrect defining of elements in relation to the type of works.
\end{abstract}

Key words: BIM, cost estimation, 3D virtual model.

\section{Introduction}

BIM (building information modeling) is a digital representation of a construction process which enables information exchange and cooperation through the use of a digital format [1], and which serves as a common source of information about a particular building. Using the BIM system in the process of cost estimation allows to prepare estimations which are quicker and more accurate, as the complete set of data on the structure is gathered in a unique software package. The employment of BIM also permits to fully/partially render construction cost estimations automatic. The aim of the article is to present problems which are related with the application of cost estimations which use the BIM system in Poland. The authors of this article took part in works carried out in Poland which

Corresponding author: Krzysztof Zima, Ph.D., research fields: cost estimation, building information modeling, design and build and integrated project delivery. E-mail: kzima@izwbit.pk.edu.pl. attempted to create a cost estimation application which uses data stored in the BIM model. The article describes selected problems of cost estimation using the BIM concept on the basis of personal experience relating to the creation of such an application, practical cost estimation examples created with this application and studied reference literature. As a consequence of this research, the most significant current difficulties relating to the BIM-based cost estimation in Poland can be presented. A BIM-based cost application created in Poland is also depicted. Also, necessary solutions which need to be introduced in Poland are presented in the article, which would enable or simplify cost estimation processes using the BIM concept.

BIM has often been recognized as a very suitable tool for the support of planning, cost estimation and information exchange between many construction process participants, leading to the maximization of efficiency and quality and a reduction in time and 
effort [2].

The construction industry is typically slow in adopting change efficiently. BIM is an exception to that rule [3], and the important benefits by far outweigh the required investment.

The key factor for efficient implementation and use of BIM, for example in planning or cost estimation, is careful design of the actual process. In a number of books $[4,5]$ the exact scope of action and level of detailing to be extracted from the BIM model is shown. In their books, the authors demonstrate many examples of design in accordance with BIM. Comparisons shown include examples of the early level of BIM design and the level of detailing.

BIM benefits include better design coordination of drawings, clash detection, integrated information management and exchange, improvements in design quality, reduction in the cost of changes and reduction in the costs of the construction phase [6].

As an example, in terms of energy and resources, efficiency results in increased complexity of the design and planning process. Research shows that for successful realization of complex projects such as sustainable buildings, it is not only the implementation of innovative technology that is necessary, but also the design and planning of the network [7]. These same problems are presented in cost estimation.

\section{The Advantages of the BIM Concept in the Support of a Construction Investment}

The concept of BIM is to construct a virtual building, prior to construct it physically, in order to work out problems, and simulate and analyze potential impacts [8]. The 5D technology is designed for the purpose of integrated management of all critical parameters of a future construction project, from its design to its erection [9]. The information model of a building is detailed described by such principal features as Ref. [10]:

(1) 3D parametric modeling: Applications which allow to model in 3D have the advantage of parametric modeling of a project's aim, which enables the creation and editing of a model and as a result there is a smaller likelihood of errors occurring in the design;

(2) Collision detection: A 3D model, virtually representing a real space, through its building information modeling concept allows to detect collisions (clash detection) - errors in the design where, for example, surfaces collide, the continuity is broken or installations are crossed;

(3) Engineering analysis: BIM system is based upon a digital database which collects all information of a building, which can then be utilized when making investment decisions, through the execution of qualitative and quantitative analyses. Analyses relating to energy consumption, insolation and shading, future running costs and many other simulations can significantly increase the efficiency and reliability of the design and planning processes;

(4) Schedules (4D modeling): 4D BIM applications can combine network methods and schedules with 3D virtual structures. This allows to graphically represent the subsequent stages of construction works, together with their visualization and animation. The 4D schedules are useful tools in construction works planning, coordination and communication;

(5) Cost estimation (5D modeling): The information on the scope and amount of the necessary construction works, as well as actual construction costs can be related directly to every element in a 3D project. These "related costs" are parametric and dynamic, which means that any changes to the model will amend the calculations connected with quantities of the required materials, the bill of quantities and the investment's cost estimation;

(6) General information: 3D structures can also be combined with different source documentation with the use of hyperlinks. As a result, a project (a virtual model of a structure) can be extended by a range of additional data. Technical specifications, various technical data, photographs and links to manufacturers (manufacturers' websites) can serve as added value to every stage of an investment process. 
Precise information collected in one database (a file) in the form of digital data, which uses possibilities of parametric modeling, has a considerable advantage over traditional design methods. The information allows to make decisions relating to a building which is being erected at every stage of an investment process using up-to-date and complete data. Collecting information in one location simplifies the detection and removal of problems within a project, while also allowing to reduce their presence, due to the fact that technical documentation is uniform and current. The application of building information modeling concept quickens the processes of cost estimation. BIM's task is to store data in one file to guarantee their cohesion and accessibility.

\section{Advantages of Using the BIM Concept in Cost Estimations.}

Software which uses the BIM concept allows, for example, the user to prepare bills of quantities or to calculate the required amount of materials without the need to carry out manual and arduous calculations of the necessary works or materials required. All such elements are carried out automatically on the basis of data included in the model of the project which is being constructed [11].

BIM provides for the transformation of information thanks to the possibility of digital data delivery to all investment participants-starting from the initial design, through the construction to the management of the building. The BIM model is only a starting point for cost estimation processes and at present there is no such tool which could render the work of a cost estimator completely unnecessary by automatically calculating the costs using previously created design documentation. Fig. 1 shows that the BIM model can only automatically provide a section of data needed to perform cost calculation (bill of quantities, scope of calculation and list of materials), leaving the cost estimator with the remaining elements. The remaining work is dependent on the regulations relating to cost estimation and the individual assessment of the cost estimator. The cost calculation process showed in Fig. 1 is reversible. The cost estimation structure is created based on the data recorded by the designer in the model. It may be changed in case of works which are not in the model. Changes that are made to the structure of the merging of similar type are also reproduced in the model. If there is no changes in the model, cost documentation (takeoff and cost estimation) can be developed very quickly. In case of works which are in the model library marker should be separated. It must be unique. Due to the large amount of information stored by different CAD programs in the IFC (industry foundation classes) files, the marker often can not be clearly identified. Such determination shall be made at the IFC - a clear indication of the format structure for a library marker. This will open the opportunity to work

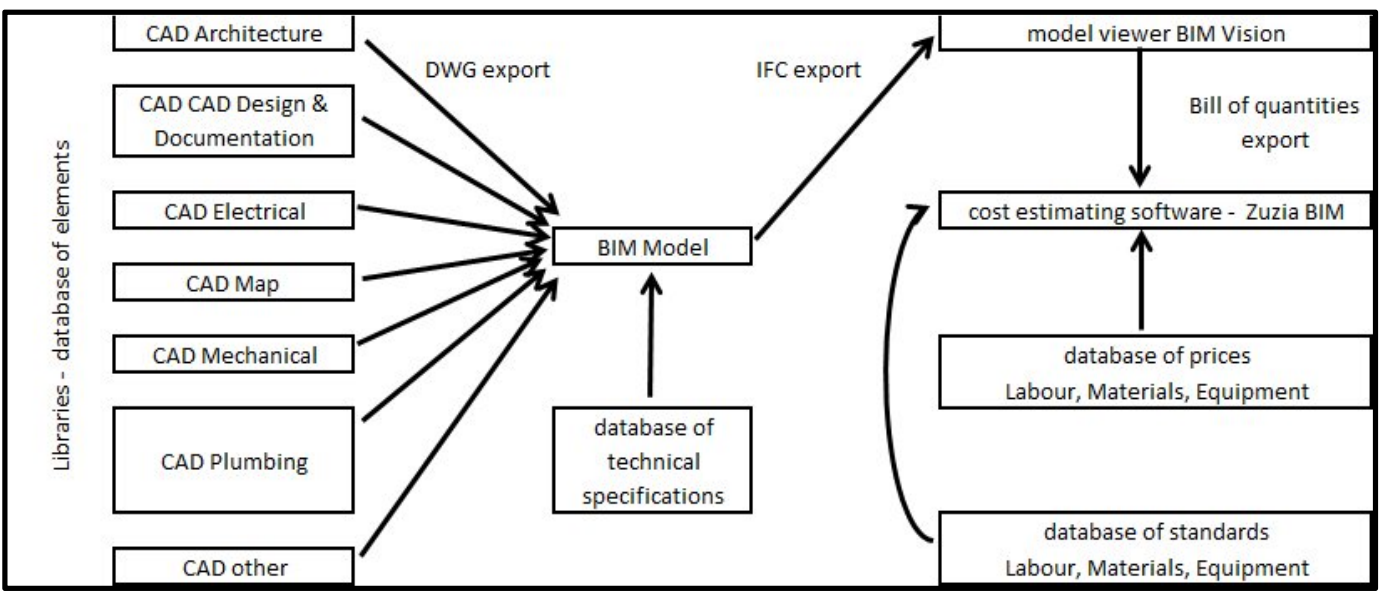

Fig. 1 Cost calculation based on the BIM concept (own source). 
model - cost estimation at the range number of iterations this same library without interfering with the already adopted structure of a model for other libraries.

The differences in the proceedings shown in Fig. 1 relate to the preparation of a bill of quantities, whose scope and quantity of works in the event of using the BIM concept are automatically sourced from the model of a building, for example by using the IFC format. The provision of data on the quantity of works, areas and cubic capacity of the individual elements is one of the most important functions offered by the BIM technology [4]. Apart from the obvious cut in the time needed to prepare a bill of quantities, another advantage of this system is the reduction of the number of errors relating to the identification of scope and calculations of the works to be carried out. Consequently, the accuracy level of a building's description using the BIM model directly translates into the accuracy level of the automatically created bill of quantities and of the cost calculation [1].

Cost calculations can be conducted throughout the whole cycle of the BIM project lifespan. The level of cost calculation detail can vary depending on the phase of an investment. Companies using the BIM technology should prepare their own internal procedures and standards for the development of structures, specifying the required level of detail for the calculations of a given stage of a project and creating frameworks to ensure the flow of coherent information from all BIM components, to be registered by individual cost items.

The initial cost calculation can be automatically performed already at the design stage, using the previously created 3D design, based on construction element libraries. Initial cost calculations, in contrast with the ones created during subsequent stages, are carried out on the basis of a concept (for example according to the house price bulletin, published by Sekocenbud for the first quarter of 2012 - a sample five-storey multi-family residential building costs approximately $552.19 € / \mathrm{m}^{2}$ or $119.68 € / \mathrm{m}^{3}$ ) and they do not require a calculation of individual elements.
As a rule, the concept phase estimates costs on a concept level, and a more detailed description of a model will mean a more detailed cost calculation [5]. The initial cost calculation can be prepared on the basis of a template created from previous examples, depending on the project type, region or structure type.

Detailed BIM-based cost calculations are created on the basis of coherent information defining the project and technical data. These calculations can be practically carried out at every stage of a project's development and they are adjusted to the report's level of detail. The BIM users need to, therefore, establish standards to represent construction components (structures, groups and elements) in a model-adapting the required level of detail to the particular stage of an investment [12]. The elements can be modeled in a general way (i.e., oak doors) or to a defined level of detail (i.e., oak doors insulated with polystyrene $25 \mathrm{~mm}$ thick, covered with acrylic paint) - Fig. 2. Objects, groups or elements can be described in a BIM model only to a certain degree. An ideal solution would be to introduce, on the basis of BIM, description standards for the elements in a project or the creation of prepared libraries of elements with their comprehensive description. Such libraries are available on the Polish market, however, they lack a certain level of description standardization, there is too few of them and they apply mostly to the finishing (there are no libraries prepared for structural elements or installations - neither commercial products nor BIM standard elements). Any additional information, which can be introduced to the model during the cost calculation stage, can be combined with elements in the external database (i.e., website pages, as it is shown in Fig. 2). The BIM-based cost calculation can be carried out in different ways-increasing the definitions of the structure in a model or with the use of unique identifiers for the structures which are linked to more detailed information stored in databases, such as Microsoft Access or Oracle [12]. 


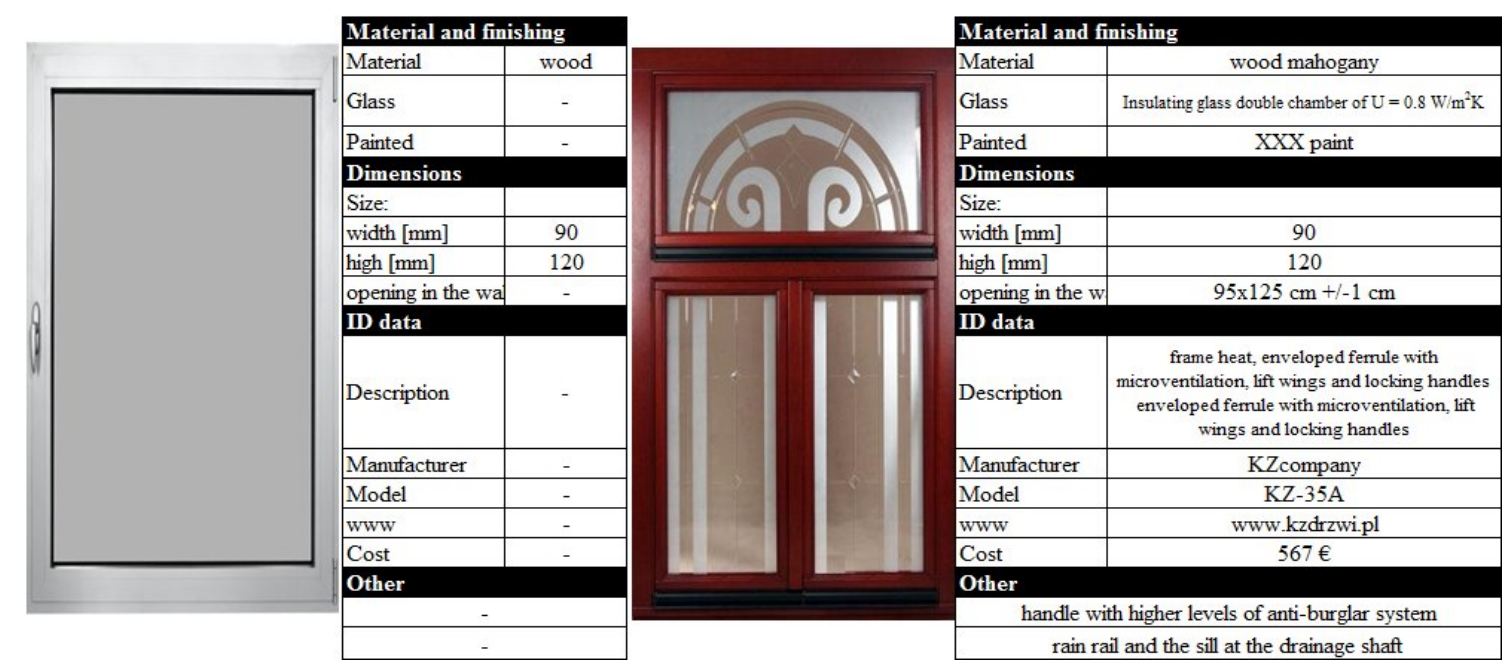

Fig. 2 Level of detail for element description—general data on universal doors and selected doors (own source).

The BIM model can describe different types of elements, i.e., structural (walls, ceilings and beams) or finishing ones (doors, windows, plaster work, etc.). That database can include a wide array of information about the product, including geometry, material, manufacturing and assembly techniques, tolerances, costs, and even information to support supply chain management, or it may include only some of these [13]. The BIM model can describe for each element abstract concepts and relations, for example, connections and locations in relation to one another, types of elements, as well as description of areas and systems of which it is a part of.

\section{Cost Valuation Using BIM in Poland}

The recently created application Zuzia BIM is used for cost estimation on the basis of a bill of quantities read directly from a virtual model created in CAD and equipped with BIM technology. This model, which contains integrated results coming from architects, design engineers and installers, is a basis for the creation of construction cost estimation. Zuzia BIM comprises two elements: BIM Vision viewer (Fig. 3a), which enables reading and virtual visualization of a building model and Zuzia 11 cost estimation system (Fig. 3b).

BIM Vision can:
(1) Read virtual models in IFC $2 \times 3$ format;

(2) Use simple geometric operations - rotate, move and zoom;

(3) Visualize a building with different degrees of transparency (solid body with opaque walls, partially transparent walls and the so-called lattice mode, where only edges are visible);

(4) Present a scope of works according to the prepared project for all sectors;

(5) Remove a part of a model and discard selected model components;

(6) Calculate the quantity of works.

A transfer can then be carried out to Zuzia 11 cost calculation system. This system is a conventional system which is equipped with all necessary functions, including databases in the form of normative catalogues and pricelists. In order to simplify the process of cost calculation, there is a possibility to visualize selected items of the cost calculation by highlighting the required elements of a model. The highlighted elements can be viewed against other components, they can also be removed from a model or only the highlighted elements can be displayed. The viewer operates independently of the system where the virtual model was created. Individual elements of a model, after data is imported from the viewer, serve as items in Zuzia BIM cost calculation system. 


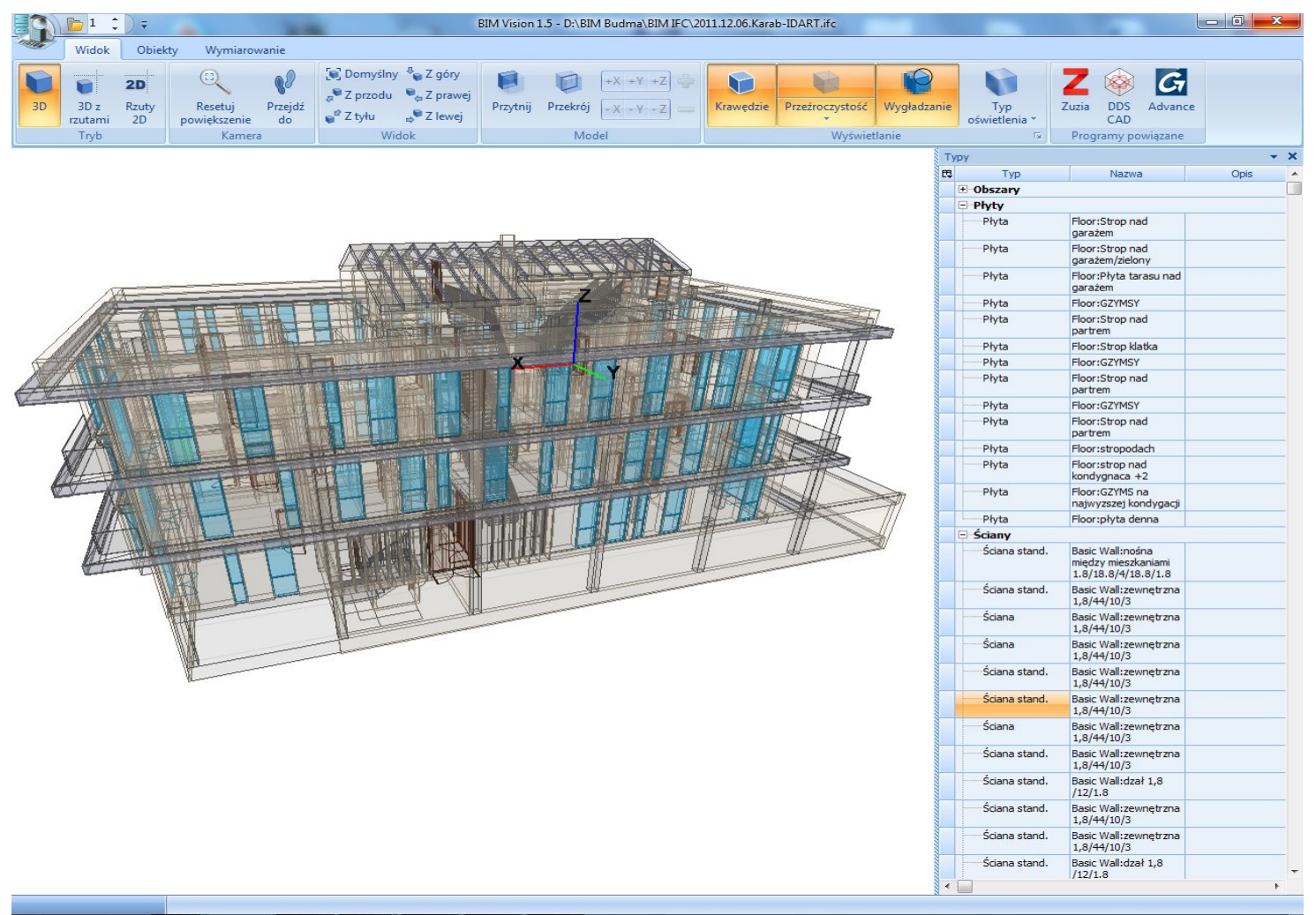

(a) BIM vision browser - a part of Zuzia BIM cost estimation application

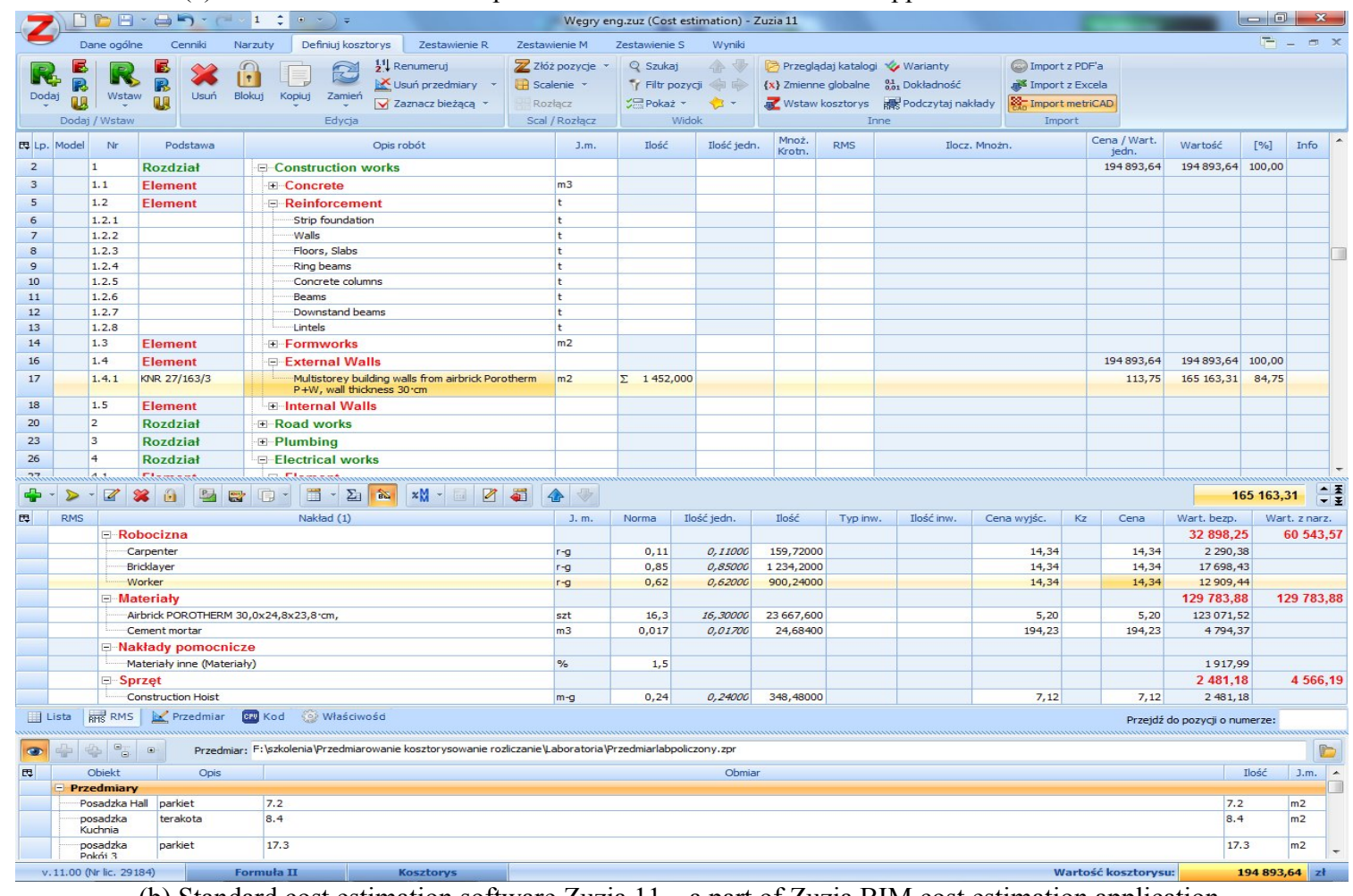

(b) Standard cost estimation software Zuzia 11-a part of Zuzia BIM cost estimation application

Fig. 3 Zuzia BIM comprises two elements. 
All BIM elements of the same type create one BIM position. Further proceedings are related to the estimation of cost estimation items as part of a cost calculation system according to the accepted reintegration level for elements or construction works. The suitability of the above-mentioned application depends to a large degree on what data is delivered by the BIM model.

\section{Problems with Cost Estimation Using the BIM Concept}

Practical utilization of the BIM concept potential is at present inconsequential in Poland. Lack of awareness of investors, designers and contractors renders the practical employment of the BIM's advantages negligible. Another obstacle is that there are no system solutions prepared that would enable the use of a building model created using the BIM concept.

The task of a designer is to establish the structure of a building and decide which elements belong to a given floor, roof, wall, etc.. Poland does not have any guidelines on methods and levels of detail which are required in design documentation. When using Zuzia BIM application to provide automation for the works, a certain method of element description is needed. The biggest problem in cost estimation using BIM is the appropriate design of elements in a BIM model by designers. This issue will be explained using the example of reinforcement works. Reinforcement bars have been defined by a designer as elements hollow in the middle - thin-walled sections (Fig. 4). This resulted in a problem relating to the preparation of the bill of quantities from the BIM model. If the rebars were not hollow, the calculation of their quantity (weight in tons) would be automatic (using the volume and specific gravity of steel - provided by the user).

Another issue which can serve as an example is a beam which forms a part of a monolithic floor slab and the method of calculating concrete and reinforcement works (Fig. 5). If the designer specifies in the figure the quantity of concrete works belonging to the floor slab and to the beam, then the reinforcement bars of the beam and the floor slab intercross [5]. The advice of a cost estimator is then required to solve the problem of the bill of quantities calculation.

Reinforcements which are defined as one element for the whole building with no division into reinforcement for continuous footing, spot footing, beams, slabs, etc. (Fig. 6) will also pose a considerable problem. If reinforcements are not assigned to individual structural elements made from reinforced concrete, a future cost calculation will be made more difficult as it will require the reinforcement bars to be divided into elements.

The difficulties relating to the specification of estimated elements can also be caused by the designers marking repeated elements - for example, walls which are not divided correctly into separate floors. An example of such incorrect assignment of walls to one of the layers using the CAD software is shown in Fig. 7.

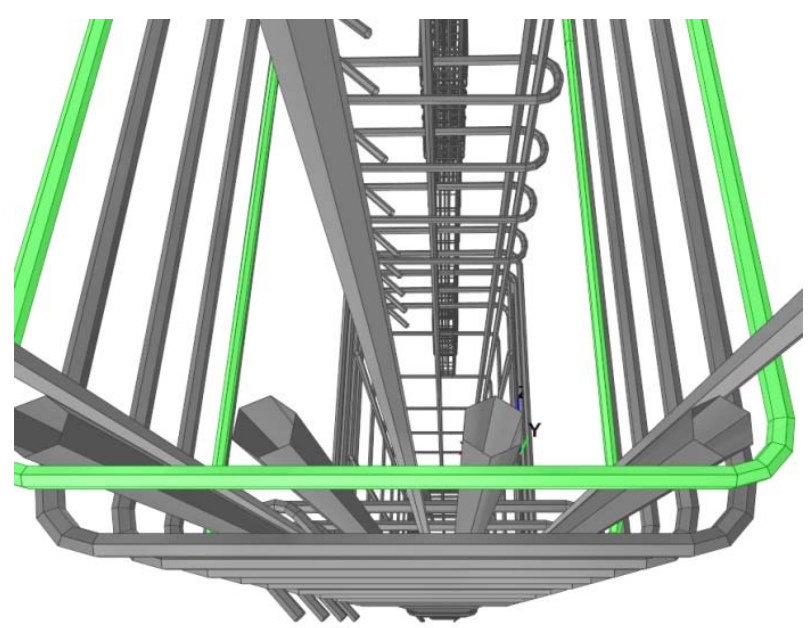

Fig. 4 Reinforcement erroneously introduced into the model-a thin-walled section instead of reinforcement bars which are not hollow.

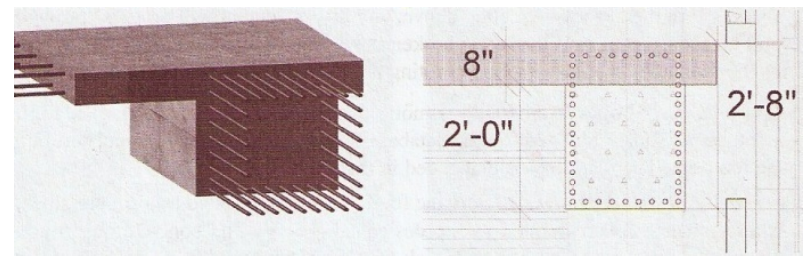

Fig. 5 Views of the beam and slab connection [5]. 


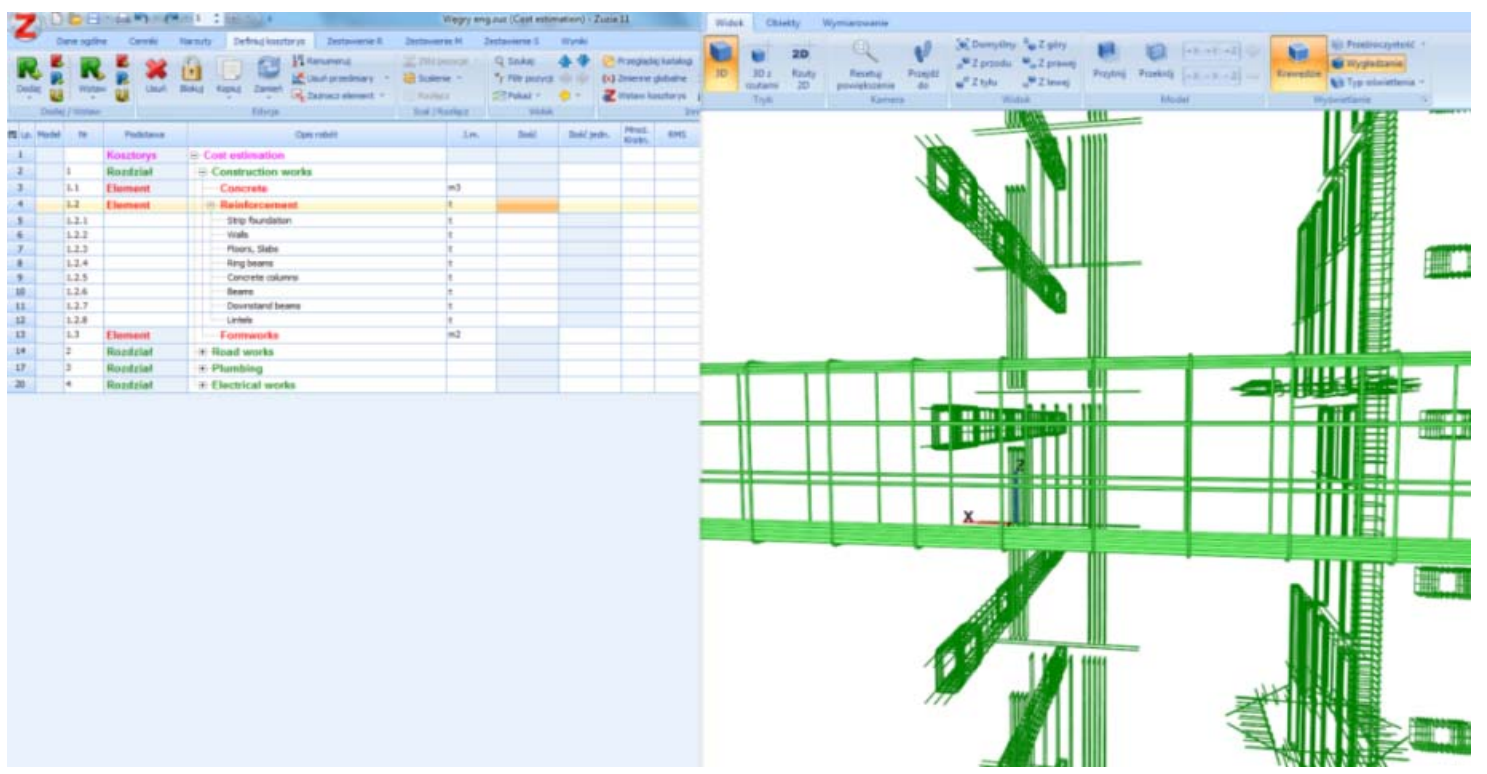

Fig. 6 Reinforcement bars defined as one piece without separation on foundations, walls, ceilings, etc..

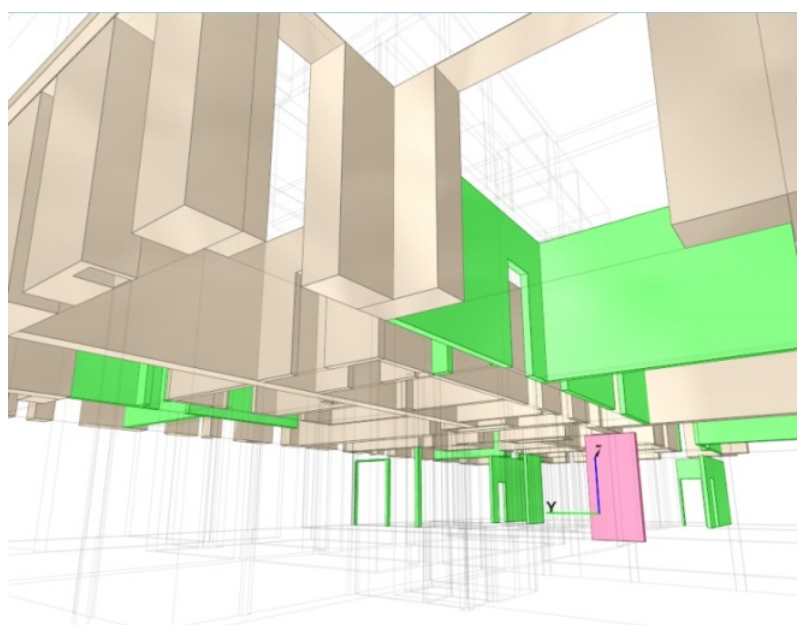

Fig. 7 Walls of one type assigned to two different floors.

The reasons for other problems related with the BIM-based construction works cost estimation are among others:

(1) defining a few cost calculation items as one element (i.e., stairs defined as one element which includes the structure and balustrades);

(2) incorrect defining of elements in relation to the type of works (i.e., elements of sanitary fixtures assigned to the chapter "construction works" instead of to "water and sewage installations");

(3) incorrect division of one element into a few smaller parts defined in different layers, as this causes the works of the same type to be valued on a few different occasions.

In addition, the designers do not model all construction elements. That is why elements like excavations, shuttering or reinforcement works will not form a part of most of the BIM models. It is usually the cost estimator who introduces these elements and the related costs. The BIM model does not as a rule include non-material and legal costs, general requirements, indirect costs as well as means and methods of building. BIM on its own does not provide a comprehensive estimation of total costs of a project. The cost estimation automation process so far has been encountering obstacles related to the bill of quantity calculation.

The lack of the required level of detail for the documentation description is combined with a lack of any design classification enabling the preparation of bills of quantities, cost estimations and the comparison of cost documentation. The classifications which can be found in Poland are used solely for statistical purposes. Currently, research is being carried out in relation to works systematics which can be used practically and the already existing systematics are being adapted, i.e., Omni class. The above-mentioned 
classifications should reflect the structure of a building, for example a division into floors, segments and other characteristic components of a building, as this will simplify the identification of elements and the use of documentation. In practice, it all looks slightly different-Frequently, a designer includes the walls of the next floor to the floor below or introduces erroneous terms which are then transported to the IFC file. The article authors also have in their experience examples of designers incorrectly rescaling some of the dimensions, which results in calculation errors of, for example, an area or volume. Consequently, there exists a need to verify and calculate these values regardless of the values which are entered into IFC by CAD systems. An example of such file is shown in Fig. 8.

Another problematic factor is the lack of element libraries created with the BIM concept in mind. There are a number of libraries of finishing and furnishing elements for a building available on the market, however, there is a decisive need for structural elements (foundations, walls, ceilings, etc.). As a result, there are considerable difficulties in combining price databases, technical specifications and other data with the particular elements of database libraries. The databases need to include many kinds of solutions, for example, walls need to be listed in such libraries, and they need to relate with the appropriate cost databases. A separate problem which originates from the existing cost estimation methodology is the lack of price databases which agree with element libraries. BIM

\begin{tabular}{|l|l|r|}
\hline IfcBuildingStorey & '1. Level 0 (+3670mm)' \\
\hline IfcWallStandardCase & External Wall & \\
\hline DCMaterialNode & 'Plaster' & 5,00 \\
\hline & 'Brick' & 120,00 \\
\hline & 'Foamed Polystyrene' & 50,00 \\
\hline & 'Concrete Block' & 240,00 \\
\hline & 'Plaster' & 15,00 \\
\hline IfcQuantityLength & 'Width' & 430 \\
\hline IfcQuantityLength & 'Height' & 3670 \\
\hline IfcQuantityLength & 'Length' & 7372,6896 \\
\hline IfcQuantityArea & 'GrossSideArea' & 27,057771 \\
\hline IfcQuantityArea & 'NetSideArea' & 27,057771 \\
\hline IfcQuantityVolume & 'GrossVolume' & 11,292013 \\
\hline
\end{tabular}

Fig. 8 A fragment of the IFC file, with hierarchical structure [14]. based cost estimation allows to perform bill of quantities automatically. BIM cost estimating is approximately $30 \%-40 \%$ shorter than non-automatic methods. Solving the problems outlined in the article will shorten the cost calculation procedure another $5 \%-10 \%$ in average.

\section{Conclusions}

BIM does not eliminate the requirement of a correct cost calculation to be performed by a cost estimator, it only supports the cost estimation process itself. At is most basic level (which has a direct effect on cost calculation), the BIM concept allows to virtually visualize a structure and it collects information on dimensions, areas and cubic capacities of a building. The BIM concept, therefore, provides at least a partial - and at the level of simplified calculations a complete, automation of the works bill of quantities, and in this context BIM is a revolutionary solution. BIM technology allows to integrate all sectors which collaborate on a given project. The BIM based cost calculation procedure shortens the time required to prepare a detailed cost estimate, as it can resort to the data obtained from the virtual model of a building. It is particularly helpful if the model is amended by designers, as this presents an opportunity to effectively utilize the relationship between an executed change as its cost. The application of the possibilities provided by BIM based cost calculation applications is to a great extent connected with design appropriateness. The problems outlined in this article and related with the BIM-based cost calculation software, which became apparent after their short trial period in Poland, are by and large caused by the errors made by designers in descriptions, figures or in the assignment of elements to the appropriate layers in the project. The introduction of a common format for the description of construction works and a uniform standard of design, as well as gaining of experience by the designers combined with a change in thinking about projects, should in the future eliminate a majority of these issues. 
What is required, however, are system alterations and training in regard to correct design procedures. At present, Poland is only at the beginning of its journey, which leads to suitable and common application of the benefits offered by the BIM concept.

\section{References}

[1] C. Eastman, Building Product Models: Computer Environments Supporting Design and Construction, CRC Press, Boca Raton FL, 1999.

[2] R. Sebastian, L. van Berlo, Tool for benchmarking BIM performance of design, engineering and construction firms in Netherlands, Architectural Engineering and Design Management 6 (2010) 254-263.

[3] G. QipingShen, P. Brandon, A. Baldwin, Collaborative Construction Information Management, Taylor \& Francis, London, 2009.

[4] B. Hardin, BIM and Construction Management—Proven Tools, Methods, and Workflows, Wiley Publishing Inc., Indianapolis, USA, 2009.

[5] W. Kymmell, Building Information Modeling: Planning and Managing Construction Projects with 4D CAD and Simulations, McGraw-Hill, USA, 2008.

[6] K. Barlish, K. Sullivan, How to measure the benefits of BIM-A case study approach, Automation in Construction 24 (2012) 149-159.

[7] I. Kovacic, L. Oberwinter, BIM-supported, lifecycle-oriented design for energy efficient industrial, facility-A case study, in: Proceeding of Creative Construction Conference, Budapest, Hungary, June 30-July 3, 2012, pp. 329-339.

[8] D. Smith, An introduction to building information modeling (BIM), Journal of Building Information Modeling 9 (2007) 12-14.

[9] M. Kozlovská, Innovation of construction designing systems, Quality Innovation Prosperity 12 (2) (2008) 19-26.

[10] M. Juszczyk, K. Zima, Building information modeling in construction process, in: TECHSTA 2010-Management and Technologies for Sustainable Development in Building Industry, Prague, 2010, pp. 15-17.

[11] V. Popovas, L. Ustinovichius, S. Mikalauskas, Technique for computer aided evaluation of economic indicators of a construction project, in: The 8th International Conference "Modern Building Materials, Structures and Techniques", Vilnius, Lithuania, May 19-21, 2004. pp. 242-248.

[12] L. Sabol, Challenges in Cost Estimating with Building Information Modeling, Design and Construction Strategies, 2008, http://www.dcstrategies.net/pdf /2_sabol_cost_estimating.pdf (accessed Apr. 11, 2012).

[13] R. See, Building information models and model views-Part 1, Journal of Building Information Modeling 9 (2007) 20-25.

[14] A. Tomana, Integration of design costing using BIM platform, Civil and Environmental Engineering 2 (3) (2011) 401-406. 